\title{
Tecnologias Digitais: Revisão Sistemática da Literatura Sobre o Uso de Jogos Digitais na Educação
}

\author{
Carlos Alberto Lopes Junior
}

Campus Pau dos Ferros - Instituto Federal de Educação, Ciência e Tecnologia do Rio Grande do Norte (IFRN) - BR 405, KM 154 - Pau dos Ferros - RN - Brasil

carlosalberto.ljoficial@gmail.com

\begin{abstract}
This article presents a Systematic Literature Review - RSL, of the scientific articles published in the Annals of the Congress about Technologies at Education CTRL $+E$, in its previous editions (2016 - 2019). Analyzing the scientifics researchs on practical applications with digital games in education. Checking, which ones were used, the levels of schooling and the disciplines, as well as, the report on the use of these games. The results were classified as satisfactory, being well evaluated in the analyzed articles, presenting a multiplicity of available games, which can be worked in the most different educational levels, and in the diverse school subjects.
\end{abstract}

Resumo. Este artigo apresenta uma Revisão Sistemática da Literatura - RSL, dos artigos científicos publicados nos Anais do Congresso sobre Tecnologias na Educação CTRL + E, em suas edições anteriores (2016-2019). Analisando as pesquisas cientificas sobre aplicações práticas com jogos digitais na educação. Verificando, quais foram utilizados, os níveis de escolaridade e as disciplinas, bem como, os relatos sobre o uso desses jogos. Os resultados foram classificados como satisfatórios, sendo bem avaliados nos artigos analisados, apresentando uma multiplicidade de jogos disponíveis, os quais podem ser trabalhados nos mais diferentes niveis educacionais, e nas diversas disciplinas escolares.

\section{Introdução}

Com o passar dos anos, os processos de condução e construção nas mais distintas áreas, sejam elas econômicas, políticas ou sociais, veem sendo modificados, muito em virtude da globalização e o avanço do progresso tecnológico. Assim sendo, o meio educacional, deve estar inserido dentro desse novo contexto de organização e flexibilização, que os processos como um todo passam a exigir, sejam das modalidades e/ou as novas formas pedagógicas de educação, para fazer frente a essas novas demandas o processo de ensino e aprendizagem também tem que se adaptar.

Nesse contexto, o processo educativo e as práticas pedagógicas devem estar alinhados para o desenvolvimento dos saberes dos alunos. Desenvolver no educando seu cognitivismo, permitindo que tragam suas vivencias do seu dia a dia e integre aos saberes educativos e construa seus próprios saberes. Trabalhando de forma que além de adquirir o conhecimento, os alunos saibam colocar em prática estes aprendizados. Sabendo reconhecer e lidar com a pluralidade, seja do ponto de vista cultural, étnico ou social, não só pensando em si, mais também na coletividade [Brasil 2018].

No entanto, existe muitas vezes uma lacuna entre a escola e aluno. A cultura atual tem que ser levada em conta no processo educativo. Existir mais ambientes propícios de 
interação, troca de ideias entre docente e aluno. Atualmente, a educação transpassa as paredes das escolas, isso não é mais exclusividade dos ambientes escolares. Entender e trazer a cultura dos alunos para as práticas pedagógicas, é aproximar, facilitar o processo de ensino e aprendizagem. Tendo os docentes no uso das tecnologias digitais, um caminho a ser incorporado como auxílio em suas práticas pedagógicas [Sousa, Miota e Carvalho 2011].

Nesse sentido, dentre os diversos dispositivos tecnológicos disponíveis e que podem ser utilizados como suporte das práticas pedagógicas, destacamos os jogos digitais. Os quais despontam como sendo importantes ferramentas de apoio ao processo educacional. Assim sendo, em Carvalho (2018), constata-se que existe uma grande diversidade de tipos de jogos (ação, aventura, lógica, memoria, dentre outros), com a capacidade de desenvolver nos jogadores, diversas habilidades a depender de cada gênero escolhido, tais como: planejamento e tomada de decisões, resolver problemas, trabalho em equipe, liderança. Dessa maneira, cabe ao professor analisar e escolher o jogo que se adapta melhor aos objetivos de aprendizagem pretendidos.

Dentro dessa perspectiva, a motivação desse estudo centra-se no interesse na temática das tecnologias digitais, em especial estudar os jogos digitais. Buscando, conhecer o cenário pedagógico/científico em que essas ferramentas estão sendo utilizadas. Destaco ainda, como motivação, ser atualmente gestor (Coordenador de Apoio Acadêmico) no IFRN - Campus Pau dos Ferros. Como também, aluno de Mestrado em Ciências da Educação, com especialidade em Tecnologias Educativas, Uminho/PT.

Nesse contexto, este artigo visa ampliar meus conhecimentos e buscar norte para pesquisas futuras na temática sobre tecnologias digitais, em especial os jogos digitais. Para isso, é importante conhecer sobre o que os demais pesquisadores estão pesquisando/divulgando cientificamente. Assim, o objetivo geral é: fazer uma análise de pesquisas cientificas acerca das aplicações práticas com jogos digitais na educação. Como objetivos específicos: Verificar quais os jogos digitais foram apresentados nesses artigos? Quais os níveis de escolaridade e as disciplinas os jogos foram trabalhados? Quais os relatos sobre ao uso dos jogos digitais aplicados em seus estudos?

Para isso, optou-se em fazer uma Revisão Sistemática dos artigos científicos publicados nos Anais do Congresso sobre Tecnologias na Educação CTRL + E, em suas edições anteriores (2016 - 2019). Com foco nos artigos científicos completos, com aplicação prática de jogos digitais.

Por fim, o artigo está estruturando da seguinte forma: no tópico 1 Introdução, o qual faz uma breve contextualização da temática, motivação do estudo, objetivos e como o artigo se estrutura. Por seguinte temos 2 Método da pesquisa, o qual contextualiza o método escolhido, as questões de pesquisa, identificação da base de dados, estratégias e palavras-chaves de busca, critérios de inclusão e exclusão dos artigos, critérios para análise e escolha dos artigos e por fim, os artigos selecionados. No 3 Análise e discursão dos resultados, apresenta-se as análises e discursões dos resultados da RSL, divididos em subtópicos: 3.1 Quais os jogos digitais foram apresentados nas pesquisas dos artigos científicos? 3.2 Em quais níveis de escolaridade e disciplinas os jogos foram trabalhados? 3.3 Quais os relatos apresentados nos artigos sobre o uso dos jogos digitais aplicados em seus estudos? No tópico, 4 Considerações finais, apesenta-se os relatos finais do artigo, e por fim as Referências utilizadas. 


\section{Método}

Como apresentado antes na introdução, este artigo tem como objeto metodológico realizar uma Revisão Sistemática da Literatura - RSL. Uma forma de pesquisa, na qual conforme Sampaio e Mancini (2007, p. 84), "disponibiliza um resumo das evidências relacionadas a uma estratégia de intervenção específica, mediante a aplicação de métodos explícitos e sistematizados de busca, apreciação crítica e síntese da informação selecionada".

Nesse contexto, para realizar a RSL desse artigo, seguimos algumas etapas descritas no estudo de Sampaio e Mancini (2007), dentre elas: definição da pergunta cientifica, identificação da base de dados, definição das estratégias e palavras-chaves de busca, estabelecer critérios para a seleção dos artigos, analisar e avaliar os estudos, apresentar uma conclusão da RLS.

Assim sendo, nesse estudo, temos a seguinte estruturação das etapas da RSL:

- Questões de pesquisa: Questão 1: Quais os jogos digitais foram apresentados nas pesquisas dos artigos científicos? Questão 2: Em quais níveis de escolaridade e disciplinas os jogos foram trabalhados? Questão 3: Quais os relatos apresentados nos artigos sobre o uso dos jogos digitais aplicados em seus estudos?

- Identificação da base de dados: A Revisão Sistemática da Literatura, teve como base de dados, os artigos científicos completos publicados nos Anais do Congresso sobre Tecnologias na Educação CTRL + E, em suas edições anteriores $\left(2016\right.$ - 2019) ${ }^{1}$, com foco nos artigos com aplicação prática de jogos digitais.

- Estratégias e palavras-chaves de busca: Acessar o site do Congresso em cada edição do evento e acessar o tópico onde fica dispostos os artigos. Utilizou-se na busca dos artigos, palavras-chaves: Jogo (s), Game (s).

- Critérios para inclusão dos artigos: 1. Artigos no período de 2016 - 2019; 2. Artigos completos; 3. Artigos que em seu título apresenta-se o termo Jogo (s), Game (s); 4. Artigos com aplicação prática de um jogo digital na educação.

- Critérios para exclusão dos artigos: 1. Artigos que não contemplem os critérios de inclusão anterior; 2. Artigos repetidos; 3. Artigos que contemplem apenas revisão sistemática ou de revisão teórica da literatura, ou ainda pesquisas não concluídas.

- Análise e a avaliação dos estudos: Foram feitas obedecendo os pontos apresentados anteriormente, além dos artigos finais selecionados haver uma exploração mais concisa dos estudos, como leituras e fichamentos. Por fim, foram feitas as conclusões da RSL.

Em suma, ao realizamos a RSL, em etapas, obedecendo os critérios já apresentados, de forma que se apresentam os dados na tabela 1 a seguir, onde: primeiro acessamos os sites do evento por ano de realização (links disponíveis na nota de rodapé). Na etapa 1, foram encontrados conforme a segunda coluna da tabela, o total de 252 (duzentos e cinquenta e dois) artigos dentro do critério de inclusão 1 (artigos no período de 2016 - 2019), ou seja, artigos completos e resumidos. Na etapa 2, foram encontrados conforme a terceira coluna da tabela, o total de 176 (cento e setenta e seis) artigos dentro

\footnotetext{
${ }^{1}$ Anais de 2016, disponível em: http://ceur-ws.org/Vol-1667/. Anais de 2017, disponível em: http://ceurws.org/Vol-1877/. Anais de 2018, disponível em: http://ceur-ws.org/Vol-2185/. Anais de 2019, disponível em: https://sol.sbc.org.br/index.php/ctrle/issue/view/486. Todos os anais acessados em: abr. 2020.
} 
do critério de inclusão 1 e 2 (artigos completos), ou seja, excluído os artigos resumidos. Na etapa 3, utilizando na busca palavras-chaves jogo (s) e game (s) foram encontrados conforme a quarta coluna da tabela, o total de 16 (dezesseis) artigos dentro do critério de inclusão 1, 2 e 3 (artigos que em seu título apresenta-se o termo Jogo (s), Game (s)). Na etapa 4, foi feita uma leitura ampla dos artigos, a fim de observar se os jogos abordados nos trabalhos eram digitais e se havia uma aplicação prática deles em sua abordagem. Assim, conforme a última coluna da tabela, foram selecionados 08 (oito) artigos dentro de todos os critérios de inclusão.

Tabela 1. Seleção dos Artigos

\begin{tabular}{|c|c|c|c|c|}
\hline Ano do Evento & $\begin{array}{c}\text { Artigos dentro } \\
\text { do critério de } \\
\text { inclusão 1 }\end{array}$ & $\begin{array}{c}\text { Artigos dentro } \\
\text { dos critérios de } \\
\text { inclusão 1 e 2 }\end{array}$ & $\begin{array}{c}\text { Artigos dentro } \\
\text { dos critérios de } \\
\text { inclusão 1,2 e 3 }\end{array}$ & $\begin{array}{c}\text { Artigos dentro dos } \\
\text { critérios de } \\
\text { inclusão 1,2, 3 e 4 }\end{array}$ \\
\hline 2016 & 54 & 44 & 05 & 04 \\
\hline 2017 & 65 & 45 & 04 & 02 \\
\hline 2018 & 58 & 37 & 03 & 01 \\
\hline 2019 & 75 & 50 & 04 & 01 \\
\hline Total de Artigos & $\mathbf{2 5 2}$ & $\mathbf{1 7 6}$ & $\mathbf{1 6}$ & $\mathbf{0 8}$ \\
\hline
\end{tabular}

Fonte: Elaborado pelo autor (2020).

Ressalta-se, que os artigos foram excluídos de acordo com os critérios de exclusão descritos anteriormente. Desse modo, esses 08 (oito) artigos foram objetos de uma análise mais completa de seus estudos, fazendo leituras, apontamentos, fichamentos dos elementos essenciais para identificação e entendimento do estudo científico em análise e atingir os objetivos desse artigo, em responder as suas questões de pesquisa.

Assim sendo, reunimos na tabela 2 a seguir, a descrição dos artigos estudados, onde destacamos o título, autores e ano do evento em que foi submetido os artigos. Assim como, colocou-se um código de identificação para cada um desses artigos.

Tabela 2. Artigos selecionados

\begin{tabular}{|c|c|c|c|}
\hline $\begin{array}{l}\text { Código de } \\
\text { Identificação }\end{array}$ & Título & Autores & $\begin{array}{c}\text { Ano } \\
\text { do } \\
\text { Evento }\end{array}$ \\
\hline A1 & $\begin{array}{l}\text { Letramento digital no ensino de língua portuguesa } \\
\text { em uma escola do semiárido potiguar: os jogos } \\
\text { educativos na mediação do ensino-aprendizagem }\end{array}$ & $\begin{array}{l}\text { Alexandre Caitano, } \\
\text { Edjane de Azevêdo, } \\
\text { Marlla Viana }\end{array}$ & 2016 \\
\hline A2 & $\begin{array}{l}\text { Experiencia com ensino de programação e } \\
\text { aplicação de jogos digitais educativos }\end{array}$ & $\begin{array}{l}\text { Jéssica Laísa Dias da } \\
\text { Silva, Isabel Dilmann } \\
\text { Nunes, Luzivone } \\
\text { Lopes Gomes }\end{array}$ & 2016 \\
\hline A3 & $\begin{array}{l}\text { Engajamento no aprendizado baseado em jogos } \\
\text { digitais: estudo de caso com o jogo "Matemática } \\
\text { Fácil" }\end{array}$ & Alvaro Silva & 2016 \\
\hline A4 & $\begin{array}{l}\text { Ensinando programação de computadores com o } \\
\text { auxílio de jogos digitais para alunos do } 2^{\circ} \text { e } 3^{\circ} \text { ano } \\
\text { do ensino fundamental }\end{array}$ & $\begin{array}{c}\text { Fabiana Marinheiro, } \\
\text { Ivanovitch Silva, } \\
\text { Charles Madeira, } \\
\text { Sandro Cordeiro, } \\
\text { Danielle Souza, } \\
\text { Patrícia Costa, } \\
\text { Gildene Fernandes }\end{array}$ & 2016 \\
\hline
\end{tabular}




\begin{tabular}{|c|l|c|c|}
\hline A5 & $\begin{array}{l}\text { Jogos Infantis e pensamento computacional: em } \\
\text { busca de um conjunto de diretrizes de design }\end{array}$ & $\begin{array}{l}\text { João Paulo da Silva, } \\
\text { Taciana Pontual } \\
\text { Falcão }\end{array}$ & 2017 \\
\hline \multirow{3}{*}{ A6 } & $\begin{array}{l}\text { Avaliação de aprendizagem após o uso de jogo } \\
\text { educativo para educação permanente em } \\
\text { enfermagem }\end{array}$ & $\begin{array}{c}\text { Luciana Schleder } \\
\text { Gonçalves, Jossandro } \\
\text { Rodrigues da Cruz, } \\
\text { Ana Paula Magalhães } \\
\text { de Abreu de Giacomo }\end{array}$ & 2017 \\
\hline A7 & $\begin{array}{l}\text { Uma avaliação inicial do jogo para o ensino de } \\
\text { testes de software iTestLearning sob a ótica de um } \\
\text { software educativo }\end{array}$ & $\begin{array}{c}\text { Emanuel Ferreira } \\
\text { Coutinho, Carla Ilane } \\
\text { Moreira Bezerra }\end{array}$ & 2018 \\
\hline A8 & $\begin{array}{l}\text { Virtualização de jogos matemáticos: uma avaliação } \\
\text { do Cubra Doze }\end{array}$ & $\begin{array}{l}\text { Ana Caroline Santos } \\
\text { Silva, Taciana } \\
\text { Pontual Falcão }\end{array}$ & 2019 \\
\hline
\end{tabular}

Fonte: Elaborado pelo autor (2020).

\section{Análise e Discursão dos Resultados}

Nesse tópico, vamos apresentar as análises e discursões dos resultados da RSL. Inicialmente, como podemos verificar na tabela 2 apresentada no tópico anterior, temos um destaque na quantidade de artigos analisados no evento de 2016, o qual teve 04 (quatro) artigos analisados. Por seguinte, 02 (dois) artigos do ano de 2017, e 01 (um) artigo do ano de 2018, assim como, 01 (um) artigo do evento de 2019. Outro fato que nos chama a atenção, é que quase todos os pesquisadores/autores, declararam os endereços/vínculos (abaixo dos seus nomes), são de Instituições Federais de Educação. A exceção está em (A2), onde uma das autoras é do Colégio Imaculada Conceição CICDammas. Ou seja, nesses 08 (oito) artigos, com mais de 20 autores no geral, apenas uma autora não é de instituição Federal de ensino. Como podemos ver em: (A1) UFERSA, (A2) UFRN, (A3) IFRN, (A4) UFRN, (A5) UFRPE, (A6) UFPR, (A7) UFC, (A8) UFRPE.

\subsection{Quais os jogos digitais foram apresentados nas pesquisas dos artigos científicos?}

Partindo de uma análise mais detalhada dos artigos, sintetizamos na tabela 3 a seguir, os jogos utilizados nas aplicações práticas dos estudos realizados pelos pesquisadores. Desse modo, a tabela é composta por três colunas, onde a primeira apresenta o código de identificação do artigo. Já a segunda coluna, demonstra os jogos utilizados, e na última coluna da tabela, apresentamos algumas informações sobre os jogos, retirados dos próprios artigos, ou seja, uma citação direta de partes do texto.

Tabela 3. Jogos Digitais apresentados nos artigos

\begin{tabular}{|c|c|c|}
\hline $\begin{array}{c}\text { Código de } \\
\text { Identificação }\end{array}$ & Jogos & Informações sobre os jogos extraídas de trechos dos artigos \\
\hline A1 & $\begin{array}{l}\text { 1- KhangMan } \\
\text { 2- Roda a Roda } \\
\text { 3- Soletrando } \\
\text { 4- Jogo da } \\
\text { Acentuação }\end{array}$ & $\begin{array}{l}\text { "1 - Um jogo de forca que traz palavras da língua portuguesa. } \\
2 \text { - Software onde os alunos deveriam tentar adivinhar as } \\
\text { palavras. } \\
3 \text { - Software, soletração de palavras. } \\
4 \text { - Software de acentuação de palavras adequado ao novo } \\
\text { acordo ortográfico". }\end{array}$ \\
\hline $\mathrm{A} 2$ & $\begin{array}{l}1-\text { Scratch } \\
2-\text { Reciclagem de } \\
\text { lixo eletrônico } \\
3-\text { Feche a torneira }\end{array}$ & $\begin{array}{l}\text { "1- Possibilita a criação de histórias interativas, animações, } \\
\text { jogos, músicas e o compartilhamento dessas criações na } \\
\text { Internet. }\end{array}$ \\
\hline
\end{tabular}




\begin{tabular}{|c|c|c|}
\hline & $\begin{array}{l}4 \text { - Você sabe como } \\
\text { economizar água? }\end{array}$ & $\begin{array}{l}2 \text { - Jogo teve como objetivo o entendimento sobre o que é lixo } \\
\text { eletrônico e que deveriam ser reciclados. } \\
3 \text { - De modo lúdico este jogo apresenta um labirinto na qual o } \\
\text { jogador tem que sair para conseguir fechar a torneira. } \\
4 \text { - O jogo mostra problemas do dia a dia das pessoas e soluções } \\
\text { econômicas e eficientes de como economizar água". }\end{array}$ \\
\hline A3 & Matemática Fácil & $\begin{array}{l}\text { "O jogador, para avançar de fase, resolverá questões de } \\
\text { matemática, baseadas nos números e nos operadores } \\
\text { disponibilizados pelo jogo. Jogo "Matemática Fácil" não tem o } \\
\text { objetivo de ensinar as operações da matemática fundamental, } \\
\text { nem de medir o nível de aprendizado do jogador. A proposta do } \\
\text { jogo é servir de ferramenta auxiliar para os jogadores } \\
\text { exercitarem as operações da matemática fundamental que são } \\
\text { ensinadas em sala de aula, através do método tradicional e } \\
\text { retornar informações sobre a resolução das operações". }\end{array}$ \\
\hline A4 & $\begin{array}{l}\text { Hora do Código - } \\
\text { Utilizado o (Curso 2) }\end{array}$ & $\begin{array}{l}\text { "É uma iniciativa global voltada para a desmistificação do } \\
\text { ensino da programação de computadores. No artigo a } \\
\text { abordagem prática se deu com o Curso 2: Os participantes } \\
\text { criam programas para resolver problemas e desenvolver } \\
\text { histórias ou jogos interativos que podem compartilhar com } \\
\text { outras pessoas". }\end{array}$ \\
\hline A5 & $\begin{array}{l}\text { 1- Operação Big } \\
\text { Hero - Code Baymax } \\
\text { 2- Labirinto Clássico } \\
\text { 3- CodeMonkey } \\
\text { (desafio 10) }\end{array}$ & $\begin{array}{l}\text { "1- Esse é um jogo da Disney que apresenta pequenos desafios } \\
\text { a cada estágio, fazendo com que o jogador use estratégias, por } \\
\text { meio de lógica de programação, para vencê-los. } \\
\text { 2- Esse jogo se baseia na condução de diversos personagens } \\
\text { através de labirintos. Para isso é necessário o uso de estratégia } \\
\text { e lógica de programação para se avançar no jogo. } \\
\text { 3- Nesse jogo a criança de fato escreve as linhas de código com } \\
\text { as instruções ou utiliza os botões pré-definidos que insere } \\
\text { algumas automaticamente, restando apenas completá-las com } \\
\text { seus respectivos parâmetros". }\end{array}$ \\
\hline A6 & Nurses for Safety & $\begin{array}{l}\text { "Foi desenvolvido para o treinamento de profissionais de } \\
\text { enfermagem de nível médio (técnicos e auxiliares de } \\
\text { enfermagem). O foco do treinamento é o manuseio de } \\
\text { medicamentos de alta vigilância nas UTI". }\end{array}$ \\
\hline A7 & iTestLearning & $\begin{array}{l}\text { "É um jogo educacional que visa apoiar o ensino de teste de } \\
\text { software, simulando um ambiente onde o jogador deverá } \\
\text { realizar as fases de planejamento e de projeto de teste de um } \\
\text { determinado sistema a partir de descrições feitas sobre eles". }\end{array}$ \\
\hline A8 & Cubra Doze & $\begin{array}{l}\text { "Jogo de tabuleiro. Versão digital de um jogo educacional sobre } \\
\text { as operações básicas de Matemática". }\end{array}$ \\
\hline
\end{tabular}

Fonte: Elaborado pelo autor (2020).

Ainda com base na tabela 3 anterior, vemos que foram trabalhados 16 jogos digitais, podemos perceber uma grande diversidade de jogos abordados nos diversos estudos, jogos de tabuleiro, software de programação, meio ambiente, treinamento profissional, estratégia, lógica, dentre outros. Visto ainda que, nenhum estudo aborda o mesmo jogo. Inclusive, alguns artigos trabalhando com mais de um jogo, como em (A1, A2 e A5). Cabe ainda apontar, que no artigo (A5) utilizou também o Hora do Código e disse qual o jogo tinha usado dele (labirinto clássico). Diferente de (A4) que os pesquisadores e pesquisadoras do artigo, não deixaram claro o jogo que foi trabalhado dentro do curso2. Um destaque também para o (A2), o qual trabalhou duas vertentes dos jogos digitais, uma com jovens, com ferramentas para criação/programação de jogos, e posteriormente foi aplicado os jogos criados com crianças. 


\subsection{Em quais níveis de escolaridade e disciplinas os jogos foram trabalhados?}

No contexto dos níveis de escolaridade e disciplinas onde foram trabalhadas as práticas com os jogos digitais, vemos uma síntese desses na tabela 4 a seguir. A partir de sua análise, podemos verificar na coluna central da tabela, que a maioria dos artigos apresentaram sua aplicação prática no Ensino Fundamental, ou seja, 05 (cinco) artigos, do total estudado. Sendo que, 01 artigo (A2) teve prática tanto no ensino médio, como no ensino fundamental. Desses 05 (cinco), 03 (três) nos anos iniciais (A2, A4, A5), e 02 (dois) nos anos finais (A1, A3). Observamos, uma baixa quantidade de artigos com aplicação de estudos nos demais níveis de ensino, dentre os oito estudados nesse artigo. Visto que, 01 (um) no ensino Técnico de nível médio (A6), cabe ressaltar que esse artigo trabalhou com profissionais atuantes de enfermagem, 01 (um) no ensino superior (A7). Além, de 02 (um) no ensino médio, (A8) e (A2), que como reportado antes, tem duas abordagens em diferentes níveis de ensino.

Tabela 4. Níveis de escolaridade das aplicações práticas dos jogos

\begin{tabular}{|c|c|c|}
\hline $\begin{array}{c}\text { Código de } \\
\text { Identificação }\end{array}$ & Nível de escolaridade & Disciplinas \\
\hline A1 & Ensino Fundamental $\left(8^{\circ}\right.$ Ano do ensino fundamental) & Língua Portuguesa \\
\hline A2 & $\begin{array}{c}- \text { Ensino médio, } \\
\text { - Ensino Fundamental }\left(1^{\circ}, 2^{\circ} \text { e } 3^{\circ} \text { Ano do ensino fundamental) }\right.\end{array}$ & $\begin{array}{c}\text { - Programação, } \\
\text { - Aulas de Ciências }\end{array}$ \\
\hline A3 & Ensino Fundamental $\left(8^{\circ}\right.$ Ano do ensino fundamental) & Matemática \\
\hline A4 & Ensino Fundamental $\left(2^{\circ}\right.$ e $3^{\circ}$ anos do ensino fundamental) & Programação \\
\hline A5 & Ensino Fundamental (Educação básica alunos 8 a 12 anos) & Programação \\
\hline A6 & Profissionais Técnicos de Nível Médio & $\begin{array}{c}\text { Enfermagem } \\
\text { (medicamentos de } \\
\text { alta vigilância) }\end{array}$ \\
\hline A7 & Ensino Superior (Graduação) & $\begin{array}{c}\text { Engenharia de } \\
\text { Software }\end{array}$ \\
\hline A8 & Ensino Médio (1 ${ }^{\circ}$ Ano do ensino médio) & Matemática \\
\hline
\end{tabular}

Fonte: Elaborado pelo autor (2020).

Com relação as disciplinas, observamos um grande destaque na área de informática, mais precisamente na de programação. Desde os anos iniciais do ensino fundamental, como em (A4, A5), passando pelo ensino médio (A2) e até no ensino de graduação na parte de engenharia de software. Além, de abordagens em disciplinas das grades comum curriculares, como matemática e Língua portuguesa.

\subsection{Quais os relatos apresentados nos artigos sobre o uso dos jogos digitais aplicados em seus estudos?}

Nesse tópico, apresentamos uma síntese da RSL, em relação aos relatos contidos nos artigos, esses, sobre o uso dos jogos digitais aplicadas em cada estudo. A tabela 5 a seguir, demonstra alguns desses relatos, a qual foi elaborada a partir de informações retiradas dos próprios artigos. Ou seja, uma citação direta de junção de partes dos textos para sintetizar um aparato geral sobre os resultados da aplicação das ferramentas digitais utilizadas.

A partir dos relatos extraídos de trechos dos artigos e demonstrados na segunda coluna da tabela 5 a seguir, verificamos, de maneira geral, que os jogos digitais na educação, foram avaliados de maneira positiva. Visto que, os diversos trabalhos apontam aspectos positivos aos alunos com o uso dos jogos abordados, tais como: melhoria e/ou aquisição de novos conhecimentos, características como: motivação, interação, 
empolgação, entusiasmo, engajamento, além de ser protagonistas da construção de seus conhecimentos.

Cabe uma ressalva, quanto ao (A7), apesar de maneira geral os alunos terem descritos como bom o jogo, no entanto, o jogo apresentou-se como uma ferramenta que deve ter ajustes para uma melhor usabilidade.

\section{Tabela 5. Relatos extraídos dos artigos sobre o uso dos jogos digitais utilizados nos estudos}

\begin{tabular}{|c|c|}
\hline $\begin{array}{c}\text { Código de } \\
\text { Identificação }\end{array}$ & Relatos extraídos de trechos dos artigos \\
\hline A1 & $\begin{array}{l}\text { "Com a utilização dos jogos digitais, os educandos tornaram-se protagonistas do seu } \\
\text { próprio conhecimento, respeitando e seguindo o seu ritmo de aprendizagem de forma } \\
\text { prazerosa". }\end{array}$ \\
\hline $\mathrm{A} 2$ & $\begin{array}{l}\text { "A experiência relatada neste artigo permite mostrar a motivação dos jovens com o } \\
\text { aprendizado de programação por meio da Linguagem Scratch e o desenvolvimento de } \\
\text { jogos digitais sobre a preocupação com o Meio Ambiente. Com relação a aplicação dos } \\
\text { jogos criados: as crianças se empolgaram bastante com os jogos possibilitando a } \\
\text { interação também entre elas, e mostraram o interesse pela discussão com preocupação } \\
\text { com meio ambiente na medida em que os jovens apresentaram os desafios de cada } \\
\text { jogos". }\end{array}$ \\
\hline A3 & $\begin{array}{l}\text { "O jogo recebeu boas avaliações em } 6 \text { das } 7 \text { categorias avaliadas. Uma boa avaliação } \\
\text { do jogo nas categorias Concentração, Clareza, Desafio, Autonomia, Imersão e Melhoria } \\
\text { do Conhecimento. E a categoria Interação social não foi muito bem avaliada pelos } \\
\text { alunos". }\end{array}$ \\
\hline A4 & $\begin{array}{l}\text { "Obteve resultados positivos, oportunizando as crianças o desenvolvimento de } \\
\text { diferentes habilidades e competências que ajudarão na compreensão e participação ativa } \\
\text { no mundo informatizado". }\end{array}$ \\
\hline A5 & $\begin{array}{l}\text { "Motivação, o comportamento das crianças ao jogar indicou motivação. Os jogos } \\
\text { digitais educacionais que trabalham sequências algorítmicas, como mostrado neste } \\
\text { trabalho, podem atuar de forma positiva, deixando o processo de ensino- aprendizagem } \\
\text { mais divertido". }\end{array}$ \\
\hline A6 & $\begin{array}{l}\text { "Os resultados apontam que o jogo educativo contribui para aquisição de } \\
\text { conhecimentos. Percebe-se que o uso do jogo educativo possibilitou que os participantes } \\
\text { jogadores atualizassem seu conhecimento acerca dos verificadores de segurança na } \\
\text { administração de medicamentos". }\end{array}$ \\
\hline A7 & $\begin{array}{l}\text { "De maneira geral, os alunos acharam o jogo bom. Do ponto de vista da aplicação, } \\
\text { melhorar interface, usabilidade e a comunicação com o jogador, principalmente os } \\
\text { textos, pois em algumas situações o entendimento foi confuso. O jogo iTestLearning } \\
\text { está carente de aspectos de acomodação de diferenças, aprendizado cooperativo, } \\
\text { estruturação e atividades construtivistas". }\end{array}$ \\
\hline A8 & $\begin{array}{l}\text { "Os resultados confirmam o interesse e entusiasmo dos jovens na utilização de } \\
\text { atividades lúdicas digitais atreladas a conteúdos matemáticos. Além de ter ficado } \\
\text { evidente que o jogo despertou um grau considerável de engajamento nos alunos, é } \\
\text { importante ressaltar as vantagens que o jogo digital traz em comparação a sua versão } \\
\text { física: a possibilidade de feedback imediato, amenizando assim a necessidade constante } \\
\text { de um educador, que nem sempre é viável dada a grande quantidade de alunos por } \\
\text { turma; e a possibilidade de ter um material disponível e validado, e que pode ser } \\
\text { facilmente modificado para incorporar novos aspectos motivadores, como foi o caso do } \\
\text { temporizador em cada jogada". }\end{array}$ \\
\hline
\end{tabular}

Fonte: Elaborado pelo autor (2020).

Destarte, percebe-se que os jogos digitais apresentam grande potencial como ferramentas de apoio ao ensino-aprendizagem no processo educacional. Com destaque, principalmente para as noções de lógica de programação de computadores, para as diferentes faixas etárias, inclusive para crianças dos anos iniciais do ensino fundamental. 


\section{Considerações Finais}

Esse artigo teve como proposta de estudo, ampliar meus conhecimentos e buscar norte para pesquisas futuras na temática sobre tecnologias digitais, em especial os jogos digitais. Tendo como objetivo geral, fazer uma análise de pesquisas cientificas acerca das aplicações práticas com jogos digitais na educação, a partir da Revisão Sistemática dos artigos científicos publicados nos Anais do Congresso sobre Tecnologias na Educação CTRL + E, em suas edições anteriores (2016 - 2019). Buscando, verificar quais os jogos digitais foram apresentados nesses artigos? Quais os níveis de escolaridade e as disciplinas os jogos foram trabalhados? Quais os relatos sobre ao uso dos jogos digitais aplicados em seus estudos?

Ao término dessa pesquisa, classificamos a mesma como satisfatória, visto que, os objetivos propostos no estudo foram alcançados, como demonstrados no tópico 3 desse artigo, na apresentação dos resultados e análises dos artigos selecionados. Nesse contexto, a Revisão Sistemática da Literatura apresentou-se como sendo um importante e eficiente método de pesquisa, possibilitando atingir os objetivos definidos. Desse modo, podemos concluir que, as tecnologias digitais na educação, em destaque aos jogos digitais, são ferramentas pedagógicas importantes e bem avaliados nos artigos analisados, para a melhoria dos aspectos que compõem o processo de ensino-aprendizagem. E que existem, uma variedade de jogos digitais disponíveis, os quais podem ser trabalhados nos mais diferentes níveis educacionais, e nas diversas disciplinas escolares.

Por fim, em estudos futuros, deve ser ampliada a base de análise de dados, a partir de outros eventos científicos de Educação do país e até mesmo eventos internacionais. Possibilitando uma visão mais ampla sobre o que os demais pesquisadores estão pesquisando/divulgando cientificamente, sobre a temática dos jogos digitais, no Brasil e no mundo.

\section{Referências}

Brasil (2018) "Ministério da Educação, Base Nacional Comum Curricular”, Brasília, DF: Ministério da Educação. Disponível em: http://basenacionalcomum.mec.gov.br/. Acesso em: 23 abr. 2020.

Carvalho, G. R. de. (2018) “A importância dos Jogos Digitais na Educação", Trabalho de Conclusão de Curso (Tecnólogo em Educação) - Universidade Federal Fluminense, Niterói - Rio de Janeiro, 2018. Disponível em: https://app.uff.br/riuff/bitstream/1/8945/1/TCC_GABRIEL_RIOS_DE_CARVALH O\%20\%281\%29.pdf. Acesso em: 5 mai. 2020.

Sampaio, R. F., e Mancini, M. C. (2007) "Estudos de Revisão Sistemática: Um guia para Síntese Criteriosa da Evidência Científica". Revista Brasileira de Fisioterapia, São Carlos/SP, v. 11, n 1, p. 83-89, jan/fev. 2007. ISSN 1413-3555. Disponível em: https://www.scielo.br/pdf/rbfis/v11n1/12.pdf. Acesso em: 05 mai. 2020.

Sousa, R. P. de., Miota, F. M. C. da S. C., e Carvalho, A. B. G. (2011) “Tecnologias Digitais na Educação”. 23. ed. Campina Grande: Eduepb, 2011. 276 p.

\section{Referências dos artigos incluídos na RSL}

Caitano, A., Azevêdo, E. de., e Viana, M. (2016) "Letramento digital no ensino de língua portuguesa em uma escola do semiárido potiguar: os jogos educativos na mediação do 
ensino-aprendizagem". In. Congresso Regional sobre Tecnologias na Educação, 1, (I Ctrl+e), maio 2016, Natal/RN. p. 25-33. ISSN 1613-0073. Disponível em: http://ceurws.org/Vol-1667/. Acesso em: 20 abr. 2020. [A1].

Coutinho, E. F., e Bezerra, C. I. M. (2018) "Uma avaliação inicial do jogo para o ensino de testes de software iTestLeaening sob a ótica de um software educativo". In. Congresso sobre Tecnologias na Educação, 3, (III Ctrl+e), junho 2018, Fortaleza/CE. p. 11-22. ISSN 1613-0073. Disponível em: http://ceur-ws.org/Vol-2185/. Acesso em: 22 abr. 2020. [A7].

Gonçalves, L. S., Cruz, J. R. da., e Giacomo, A. P. M. de A. de. (2017) “Avaliação de aprendizagem após o uso de jogo educativo para educação permanente em enfermagem". In. Congresso sobre Tecnologias na Educação, 2, (II Ctrl+e), maio 2017, Mamanguape/PB. p. 187-196. ISSN 1613-0073. Disponível em: http://ceurws.org/Vol-1877/. Acesso em: 21 abr. 2020. [A6].

Marinheiro, F. et al. (2016) "Ensinando programação de computadores com o auxílio de jogos digitais para alunos do $2^{\circ}$ e $3^{\circ}$ ano do ensino fundamental". In. Congresso Regional sobre Tecnologias na Educação, 1, (I Ctrl+e), maio 2016, Natal/RN. p. 300311. ISSN 1613-0073. Disponível em: http://ceur-ws.org/Vol-1667/. Acesso em: 20 abr. 2020. [A4].

Silva, A. (2016) "Engajamento no aprendizado baseado em jogos digitais: estudo de caso com o jogo Matemática Fácil”. In. Congresso Regional sobre Tecnologias na Educação, 1, (I Ctrl+e), maio 2016, Natal/RN. p. 220-231. ISSN 1613-0073. Disponível em: http://ceur-ws.org/Vol-1667/. Acesso em: 20 abr. 2020. [A3].

Silva, A. C. S., e Falcão, T. P. (2019) "Virtualização de jogos matemáticos: uma avaliação do Cubra Doze". In. Congresso sobre Tecnologias na Educação, 4, (IV Ctrl+e), agosto 2019, Recife/PE. p. 50-59. DOI https://doi.org/10.5753/ctrle.2019. Disponível em: https://sol.sbc.org.br/index.php/ctrle/issue/view/486. Acesso em: 24 abr. 2020. [A8].

Silva, J. L. D. da., Nunes, I. D., e Gomes, L. L. (2016) "Experiências com ensino de programação e aplicação de jogos digitais educativos". In. Congresso Regional sobre Tecnologias na Educação, 1, (I Ctrl+e), maio 2016, Natal/RN. p. 438-449. ISSN 16130073. Disponível em: http://ceur-ws.org/Vol-1667/. Acesso em: 20 abr. 2020. [A2].

Silva, J. P. da., Falcão, T. P. (2017) "Jogos infantis e pensamento computacional: em busca de um conjunto de diretrizes de design". In. Congresso sobre Tecnologias na Educação, 2, (II Ctrl+e), maio 2017, Mamanguape/PB. p. 345-356. ISSN 1613-0073. Disponível em: http://ceur-ws.org/Vol-1877/. Acesso em: 21 abr. 2020. [A5]. 